\title{
Automutilação no contexto escolar: Reflexões a partir da Psicanálise Lacaniana
}

\section{Self-mutilation in the school context: Reflections from Lacanian Psychoanalysis}

\author{
Rodrigo da Silva Almeida ${ }^{1 *}$, Vitor Manoel Souza Soares ${ }^{2}$, Andréa Adriana da Silva 21;
} Shayane Rosy do Carmo Farias 2 ${ }^{1}$, Sidycleide Gomes de Souza Lucena $3^{1}$; Valdir Ferreira de Lucena Filho $3^{1}$

\section{RESUMO}

Apresentamos uma leitura lacaniana sobre as práticas de automutilação no contexo escolar. Metodologicamente, trata-se de um texto de natureza ensaística, em que refletimos sobre este fenômeno a partir da concepção lacaniana de acting out e problematizamos as relações da automutilação com a angústia, a adolescência e o feminino. Compreendemos, a priori, a automutilação como um modo de subjetivação, uma forma que o falasser encontra para dizer aquilo que está encoberto quando, na dificuldade de utilizar o recurso da palavra, lesiona a si mesmo, deixando marcas expostas no corpo e também como uma mensagem que o falasser endereça ao Outro, como um pedido de socorro. Logo, propomos uma leitura da automutilação, contrapondo-se aos discursos universitário e do capitalismo, que têm predominado na atualidade, problematizando esse fenômeno a partir de uma perspectiva crítica e implicada com a dimensão sociopolítica do sofrimento psíquico.

Palavras-chave: Automutilação; Sofrimento Psíquico; Escola; Psicanálise; Lacan.

\section{ABSTRACT}

We present a Lacanian reading about the practices of self-mutilation in the school context. Methodologically, it is a text of an essayistic nature, in which we reflect on this phenomenon from the Lacanian concept of acting out and problematize the relations of self-mutilation with anguish, adolescence and the feminine. We understand, a priori, self-mutilation as a mode of subjectivation, a way that the speaking being finds to say what is hidden when, in the difficulty of using the word resource, he injures himself, leaving marks exposed on the body and also as a message that the speaking being addresses to the Other, like a cry for help. Therefore, we propose a reading of self-mutilation, in opposition to the university and capitalism discourses, which have prevailed today, problematizing this phenomenon from a critical perspective and involved with the sociopolitical dimension of psychic suffering.

Keywords: Self-mutilation; Psychic Suffering; School; Psychoanalysis; Lacan.

\footnotetext{
${ }^{1}$ UFS - Universidade Federal de Sergipe. *E-mail: rodrigoalmeidapsi@ gmail.com

${ }^{2}$ FAI - Faculdade Irecê

$2^{1}$ UFAL - Universidade Federal de Alagoas

$3^{1}$ ESTÁCIO - Universidade Estácio de Sá
} 


\section{INTRODUÇÃO}

Apresentamos uma leitura lacaniana sobre as práticas de automutilação no contexto escolar. Esta pesquisa se justifica diante do aumento da incidência da automutilação na atualidade, em diferentes instituições humanas, especialmente nas escolas, configurando um problema de saúde pública, principalmente em adolescentes do sexo feminino.

Além disso, este tema tem despertado o interesse do autor desde o período de sua graduação em Psicologia, especificamente no estágio em Psicologia Escolar, quando casos de automutilação na escola lhe foram revelados. Como resultado desta experiência foi escrito, junto com colegas de estágio, uma revisão de literatura sobre o assunto (ALMEIDA et al., 2018). Esse interesse foi resgatado posteriormente no Mestrado em Psicologia, quando realizou uma pesquisa historiografia sobre estas práticas (ALMEIDA, 2021), dando continuidade a investigação desta temática no Doutorado em Psicologia, pesquisando sobre a automutilação na escola e suas relações com o feminino, sob o olhar da Psicanálise Lacaniana.

Para a Psicanálise Lacaniana, referencial teórico utilizado nesta pesquisa, a automutilação refere-se a atos realizados pelo sujeito na tentativa de minimizar e/ou eliminar um sofrimento psíquico, em decorrência de uma angústia devastadora que é direcionada ao corpo, que funciona como objeto de descarga dessa angústia, onde o sujeito busca “[...] substituição, apaziguamento e/ou satisfação momentânea de uma dor insuportável por outra que lhe traga certo prazer" (DIAS, 2019, p. 10).

Também compreendemos a automutilação como uma forma de letra que faz uma escrita no próprio corpo, que se encontra na subjetividade, onde "[...] O corpo é como uma folha de papel, onde as experiências subjetivas podem ser escritas, algo que passa do interior para o exterior, havendo, assim uma mensagem ao Outro" (DIAS, 2019, p. 69). Tal prática se apresenta como um conflito do sujeito em sua relação com com a imagem e com a alteridade, em que se pede ajuda através de um ato, a partir da convocação do olhar do Outro (BERNAL, 2019).

Assumimos, ainda, o argumento de Lopes (2017) de que, para a Psicanálise, a automutilação deve ser, a priori, compreendida como um modo de subjetivação, uma forma que o sujeito encontra para dizer aquilo que está encoberto, quando na dificuldade de utilizar o recurso da palavra, lesiona a si mesmo, deixando marcas expostas no corpo; 
sendo um ato que funciona como um modo de estabilização frente ao mal-estar, em que a palavra não dita busca significado e ancoramento no corpo que, por sua vez, é o portavoz do seu sofrimento psíquico.

\section{PROCEDIMENTOS METODOLÓGICOS}

O presente artigo consiste numa pesquisa de natureza ensaística, através do qual são propostas reflexões, a partir da Psicanálise Lacaniana, sobre as práticas de automutilação nas escolas. Nesse sentido, discutiremos este fenômeno a partir da concepção lacaniana de acting out (LACAN, 1962-1963/2005) e iremos problematizar as relações da automutilação com a angústia, a adolescência e o feminino, tomando como base o argumento de Dias (2019) de que neste ato existe uma angústia devastadora que se converte em sintomas que são direcionados ao corpo.

Apresentamos então uma leitura lacaniana da automutilação nas escolas, sem a pretensão de explorar exaustivamente a temática e nem de trazer soluções definitivas para este fenômeno, a partir da noção lacaniana de "não-todo", conceito que o autor utiliza para fazer uma crítica às proposições universais, disseminadas pelo discurso universitário, que segundo Lacan (1969-1970/1992, p. 109): “[...] é o que mostra onde o discurso da ciência se alicerça”".

Consequentemente, a pesquisa e a escrita em Psicanálise não se propõem jamais como um saber universal, pois privilegiam sempre o singular do caso a caso, pois: “[...] O caso não é uma parcela da verdade universal; ao contrário, ele se constitui a partir daquilo que nele rejeita a universalidade que pretende governá-lo" (MARCOS, 2018, p. 97). Logo, nosso intuito com a escrita deste texto é apresentar uma abordagem alternativa dessas práticas, que não se pretende universal, a partir de uma leitura crítica.

\section{O SUJEITO ADOLESCENTE E O FENÔMENO DA AUTOMUTILAÇÃO}

A adolescência é um período de transição da infância para a vida adulta e que impõe ao adolescente situações de sofrimento psíquico em decorrência das várias cobranças que costuma se deparar, sejam elas oriundas da família, dos grupos de amigos, da escola, etc. Essa passagem costuma ser caracterizada também por uma castração dilacerante, chegando em alguns casos a uma devastação resultante de sua imagem como 
sujeito diante dos anseios e desejos do Outro. Também há apresentação ao status e sua à imagem corporal e ideológica que, muitas vezes inibe o adolescente (ARATANGY et al., 2017; DIAS, 2019; DEMANTOVA, 2020). Para, Lacan (1962-1963/2005) essa efusão é:

[...] é o terceiro lugar no sentido do que significa a inibição na vertente do movimento, assim como, na vertente da dificuldade, destacamos a referência correspondente com o termo embaraço. A efusão é a perturbação, o perturbar-se como tal, o perturbar-se mais profundo na dimensão do movimento. O embaraço é o máximo da dificuldade atingida (LACAN, 1962-1963/2005, p. 22).

Isso significa que, para Lacan (1962-1963/2005) a adolescência requer do sujeito um trabalho psíquico muito intenso, através do questionamento do complexo de castração e possibilitará que a imagem do seu corpo seja reconstruída, fazendo com que se sinta fragilizado na representação de seu eu. Dias (2019) acrescenta que são diversas e variadas as condicionantes que influenciam a vida do sujeito adolescente acometido de sintomas, muitas vezes traumáticos, angustiantes e devastadores. No caso das escolas, estas acabam funcionando como ambientes socialmente repressivos que levam esses adolescentes inibidos/embaraçados a terem uma relação desconfortável com outros sujeitos e grupos, que muitas vezes os angustiam e os desencorajam a externalizar seus afetos.

Isso corrobora, dentre outras coisas, para que se sintam impotentes para fornecer um significado aos seus significantes e/ou se deparam com objeto desconhecido ou não organizado e direcionam sua pulsão para o corpo, que representa a sua imagem perante os outros e o Outro, dentre outras formas, através da automutilação, como um pedido de socorro por não saber lidar com sua angústia devastadora (DIAS, 2019).

A angústia é um excesso de energia pulsional que circunda o aparelho psíquico e que precisa ser descarregada; é também um afeto desvinculado de sua representação original, reverberando em algo que o sujeito não consegue explicar elou nomear e nem localizar, sendo ainda um sinal para que ele possa se defender daquilo com o qual ele não consegue lidar, possuindo íntima relação com a expectativa de algo, uma indefinição e ausência de objeto e que se torna da ordem do insuportável - sinal para evitar a revivência do trauma ou o retorno da representação recalcada (DIAS, 2019).

Lacan (1962-1963/2005) define a angústia como uma sensação de que falta algo para o sujeito, que se apresenta quando a falta vem a faltar. Esse algo que falta é um objeto perdido do qual o sujeito não sabe qual é esse objeto. Porém a angústia não é sem objeto: ela possui um objeto que se assimila ao nada (DIAS, 2019). Reis (2018) complementa 
afirmando que a angústia opera produzindo uma lacuna na simbolização: “[...] uma ruptura no registro simbólico do sujeito, impossibilitando a articulação dos significantes sobre os quais se encontra sustentado todo o arcabouço subjetivo do sujeito" (p. 52).

Dessa forma, sendo o inconsciente estruturado como linguagem (LACAN, 1964/1985) é, por meio da linguagem que o sujeito articula sua verdade simbólica no âmago das relações humanas. A angústia, por outro lado, sobrepõe-se à articulação dos significantes que compõem a verdade do sujeito e produz um transbordamento que se manifesta no corpo e, consequentemente: “[...] Quando faltam significantes para nomear a angústia, não raramente aparecem os transbordamentos somáticos, expressos através de cortes, perfurações e queimaduras autoinfligidas” (REIS, 2018, p. 53). Isso significa que, para a Psicanálise, as práticas de automutilação na adolescência são o reflexo da impossibilidade de estruturação da cadeia significante. A seguir, discutiremos as práticas de automutilação nas escolas a partir da Psicanálise Lacaniana.

\section{AUTOMUTILAÇÃO NO CONTEXTO ESCOLAR: O QUE A PSICANÁLISE LACANIANA TEM A DIZER?}

No que se refere ao fenômeno da automutilação nas escolas, Dettmer e Costa (2017) afirmam que, embora não se tenham estatísticas oficiais, há razões para se acreditar no seu aumento nas escolas brasileiras. A literatura a respeito destas práticas no contexto escolar, todavia, ainda é escassa, principalmente no Brasil. Além disso, por ser considerada um tabu, costuma ser frequentemente atribuída à "mente fraca" das pessoas que fazem isso para "chamar a atenção". Interpretações como essas acabam por dificultar a ajuda para esse público, pois os seus praticantes costumam esconder o problema, principalmente devido à vergonha.

Dettmer (2018) realizou um levantamento do número de casos de automutilação em adolescentes nas faixas etárias de 13 a 17 anos, de ambos os sexos, em escolas públicas e privadas do município de Dourados, no Mato Grosso do Sul. Obteve como resultados, dentre outras coisas, que é grande o número de pessoas que recorrem a essas práticas e que a faixa etária em que a sua incidência predominou foi aos 13 anos e que o sexo feminino foi o que mais se automutilou.

Segundo a pesquisadora, o fenômeno da automutilação nas escolas, ainda tem sido predominantemente abordado a partir de uma perspectiva biomédica, produzindo, dentre 
outras coisas, uma patologização destas práticas. Também destaca que a automutilação se constitui como uma "linguagem não-verbal", cujo meio comunicacional é o seu próprio corpo, havendo a necessidade de considerar as opiniões desses adolescentes para poder: “[...] fazer emergir um discurso que grita através de corpos cortados” (DETTMER, 2018, p. 15).

Também destaca que, apesar de a automutilação ser um fenômeno psicossocial que pode acontecer em qualquer faixa etária, parece haver fortes indícios de que a adolescência é o período em que ela se torna mais frequente (DETTMER, 2018). Também está atrelada à angústia porque não há o estabelecimento de significações e de significantes e, consequentemente, acaba se convertendo em sintomas que são direcionados para o corpo (DIAS, 2019).

O sujeito adolescente, por encontrar-se em um intenso trabalho psíquico, em que a imagem do seu corpo é reconstruída, comumente tornar-se fragilizado perante o encontro com o real e com o traumático do sexo, que promoevem, inevitavelmente, angústia. Ao perceber-se impotente para fornecer significados aos seus significantes elou ao deparar-se com um objeto desconhecido e não localizado, pode vir a direcionar sua angústia para o corpo podendo ocasionar, dentre outras coisas, os atos de automutilação, como um pedido de socorro perante a situação devastadora que o assola (DIAS, 2019).

$\mathrm{Na}$ automutilação, o sujeito vivencia uma angústia que não consegue nomear e, por não possuir determinantes, se apresenta como uma experiência de intrusão de gozo, que por sua vez é diferente da satisfação e do prazer, em que o gozo pode ser extraído da própria angústia: "Há, assim, uma interrupção mediante conversão em alguma prática que traga prazer ao sujeito, tal como práticas de impulsão e de compulsão, estabelecendo uma transformação da angústia em descarga corporal” (DIAS, 2019, p. 62). Fortes (2016), ao escutar uma jovem que pratica automutilação, reproduz a seguinte fala:

[...] Quando eu termino de me cortar, a angústia depois de um tempo volta, mas vale a pena, pelo sentimento de alívio, nem que seja somente por 5 minutos. Em outro relato, lemos que, 'se escarificando, as pessoas não se punem, mas deixam 'escapar' sua dor moral'. A dor corporal é uma forma de não sentir a dor da alma. Escapa-se da dor psíquica insuportável mediante um ato de infligir-se uma dor física (FORTES, 2016, p. 103).

De acordo com Dias (2019) está presente na automutilação uma apreciação pela dor física, que permite ao sujeito desviar sua atenção de uma tensão psíquica, comumente 
através de uma angústia insuportável. Todavia, a autora destaca que essa dor psíquica não é cessada com as autolesões, porém produzem um contorno, podendo inclusive gerar prazer em decorrência do afastamento momentâneo da angústia, onde "[...] A dor psíquica é momentaneamente encoberta pelo prazer de se cortar, o que resulta em alívio da tensão angustiante com a substituição de uma tensão corporal e física” (p. 67).

A autora prossegue afirmando que alguns sujeitos descrevem "[...] sensações de satisfação, felicidade, alívio e, por vezes, se mostra fascinado com o calor do sangue escorrendo em seus cortes, não atribuindo dores aos cortes, mas sensações de bem-estar e alívio. Ele repete, então, o ato, devido a não cessação da angústia" (p. 68). O sujeito adolescente, diante das dificuldades para regular seus afetos em decorrência de sua fragilidade e instabilidade emocionais, acaba recorrendo à automutilação (DIAS, 2019). Lacan (1969-1970/1992) vai destacar também a presença de um gozo no ato de se escafificar (forma como ele nomeia este fenômeno), afirmando que:

Falo da marca sobre a pele, onde se ispira, nessa fantasia, o que nada mais é do que um sujeito que se identifica como sendo objeto de gozo. $\mathrm{Na}$ prática erótica que estou evocando, a flagelação - para chamá-la por seu nome, caso haja aqui alguém arquissurdo - o gozar assume a própria ambiguidade pela qual é no seu plano, e em nenhum outro, que se percebe a equivalência entre o gesto que marca e o corpo, objeto de gozo (LACAN, 1969-1970/1992, p. 51).

Nesse sentido, para a Psicanálise Lacaniana a automutilação não se constitui, $a$ priori, como uma patologia, apesar de ser uma prática que coloca em risco a vida do sujeito, por estar relacionada ao suicídio. Os atos autolesivos são compreendidos como um sintoma criado pelo sujeito para tentar estabilizar a angústia, marcando o momento de estabelecimento e constituição de um novo corpo, comumente relacionado às vicissitudes da partilha do corpo do adolescente com o Outro. Neste sintoma, são experienciadas sensações de prazer e satisfação que vão além da demanda psíquica do sujeito, uma vez que não produz recursos simbolizantes para essa angústia que, ao se exceder, passa a ser contida pelas automutilações (DIAS, 2019).

Além disso, Dias (2019) destaca que não é coincidência as mulheres serem o público que mais pratica automutilação. Em sua opinião, o sujeito feminino é afeito à angústia por estar na posição de mulher que, por ser não-toda, experimenta esse gozo Outro, que não é o do Um fálico, fazendo com que “[...] experimente um desvario, um 
desarrazoamento, deixando-o, assim por dizer, fora do tempo, fora do laço social" (DIAS, 2019, p. 30).

Nesse sentido, estando a angústia situada fora do simbólico, assim como o gozo do Outro, está excluída do campo da palavra sendo, consequentemente, um acontecimento do real, assim como o sintoma, considerando-se na letra a o efeito da operação da linguagem sobre o real (LACAN, 1975-1976/2007). O sujeito feminino, por estar situado no lado não-todo fálico das formas de sexuação lacanianas, propondo que o universal do que as mulheres (situadas como não-todas em relação ao falo) desejam é a loucura. Então, por serem "não-todas”, os sujeitos femininos encontram-se em desacordo, não se conformando com as determinações da sociedade e as suas crenças e assim ultrapassam os limites da norma (MIRANDA, 2017; DIAS, 2019; EULÁLIO, 2020).

Ressaltamos aqui que, para a Psicanálise Lacaniana, a posição "feminina" não equivale necessariamente a "mulher", pois para Lacan (1972-1973/2008) a posição feminina é apenas um dos efeitos decorrentes da sexuação dos sujeitos homens e mulheres (SOLER, 2005; MIRANDA, 2017; ROCHA, 2017; DIAS, 2019). Lacan (2003) também destaca que o sujeito feminino não aceita de forma tranquila a castração, por apresentar dolorosamente a devastação na mulher, que em sua relação com a mãe, parece esperar mais substância do que espera do pai.

Nesse sentido, Soler (2012) afirma que a mãe intervém a nível do corpo, se apresentando como o primeiro agente, que ela denomina de polícia do corpo, ordenando a ele "[...] onde metê-lo, o que fazer com ele, ali onde ele não deve estar" (SOLER, 2012, p. 187). Além disso, existe para a mulher outro gozo, não-todo fálico (LACAN, 19721973/2008), que pode estabelecê-la na posição de objeto e levá-la ao aniquilamento como sujeito (DIAS, 2019).

Dias (2019) complementa dizendo que o sujeito feminino apela para a sedução, fazendo uso da mascarada feminina, à espera de palavras de amor ou, ainda, engaja-se na competição fálica do ter. O resultado disso é o surgimento da "[...] devastação, então, quando ela sai da condição de mascarada feminina, sendo ultrapassada por uma cena arrebatadora, sem o recurso de 'dizer nas entrelinhas' que deveria ter sido transmitido por sua mãe como mascarada feminina" (DIAS, 2019, p. 31).

$\mathrm{Na}$ automutilação, o sujeito feminino tenta “[...] acessar o sentimento da 'carne viva', que possa conduzir, em um segundo tempo, a certa assunção do corpo como unidade e não somente como corpo informe. Os cortes oferecem a via da cinesia, da 
sensação, de propriedade de um corpo, de corporeidade" (FORTES, 2016, p. 106). Segundo Dias (2019) há uma busca pela essencialidade da fantasia que, na demora em se articular, produz acting out, as passagens ao ato, os embaraços e os afetos típicos da insuficiência da fantasia e afirma que:

$\mathrm{O}$ ato de se mutilar e se cortar apresenta-se mais comumente em meninas, pois ao se enfrentar o encontro traumático com o outro sexo, evidencia a falta fálica marcada no imaginário do corpo. Ainda, nesse sentido, entende-se que o cruzamento do feminino com a adolescência justifica a maior incidência da prática do Cutting em adolescentes do sexo feminino (DIAS, 2019, p. 68).

Isso significa que a automutilação é uma prática que busca o registro da sensorialidade, todavia não se inscreve no prazer autoerótico, tendo em vista que, para Fortes (2016, p 109) "Trata-se mais de um movimento para encontrar um modo de descarga da dor psíquica do que uma busca, seja do prazer, seja da autodestruição".

Além disso, Lacan (1962-1963/2005) nos ajuda a compreender a automutilação a partir de uma perspectiva diferente do predominante modelo biomédico. Podemos compreender essa prática a partir do conceito lacaniano de acting out, que "[...] é essencialmente, alguma coisa que se mostra na conduta do sujeito. A ênfase demostrativa de todo acting out, sua orientação para o Outro, deve ser destacada" (LACAN, 19621963/2005, p. 137), e acrescenta que:

[...] o acting out é, em essência, a mostração, a mostragem, velada, sem dúvida, mas não velada em si. Ela só é velada para nós, como sujeito do acting out, na medida em que isso fala, na medida em que poderia ser verdade. Ao contrário, ela é, antes, visível ao máximo, e é justamente por isso que, num certo registro é invisível, mostrando sua causa. O essencial do que é mostrado é esse resto, é sua queda, é o que sobra nessa história (LACAN, 1962-1963\2005, p. 138-139).

Nesse sentido, ele se apresenta ao mesmo tempo de forma evidente e de forma velada dirigindo-se para algo distante de onde está se apresentando/atuando. Pensar a automutilação como um acting out (LACAN, 1962-1963/2005) é reconhecê-la como uma mensagem que o sujeito endereça ao Outro, como um pedido de ajuda que, assim como o sintoma, é considerado uma formação do inconsciente possuidora de uma verdade, todavia estruturada como ficção, por meio da satisfação (parcial) da pulsão no retorno do recalcado (QUINET, 2008; DIAS, 2019; SOLER, 2021). 
Enquanto que o sintoma basta-se a si próprio, apresentando-se como um gozo disfarçado, o acting out se apresenta como uma demanda ao Outro, por isso Lacan (19621963/2005, p. 139) afirma que ele “[...] antes, visível ao máximo, e é justamente por isso que, num certo registro, é invisível, mostrando sua causa”. Dias (2019) corrobora dizendo que o acting out se manifesta como um 'surgir à cena', contendo uma demanda/pedido ao Outro.

De acordo com Lacan (1962-1963/2005) por um lado o acting out se apresenta numa análise como uma transferência endereçada ao analista, por este se encontrar no lugar de Outro, por outro lado ele se apresenta fora do contexto de análise como uma mensagem direcionada ao Outro, demandando a sua atenção, como um pedido de socorro. Por isso a automutilação é compreendida, tal como propõe Dias $(2019$, p. 66) “[...] como um discurso na fala corporal do sujeito, como uma mensagem, visando a cessação da angústia".

Diante disso, a Psicanálise nos ajuda a compreender a automutilação a partir de uma perspectiva crítica, sem patologizar, nem rotular e nem estigmatizar os sujeitos praticantes e também a pensar na promoção da saúde mental em nossas escolas, tendo em vista que essas instituições também contribuem para o sofrimento e adoecimento psíquico dos sujeitos que delas fazem parte, especialmente os alunos.

Epiphanio e Guimarães (2019), acreditam que um dos motivos da alta incidência das práticas de automutilação nas escolas é a não existência de um ambiente que acolha as diversas formas de sofrimento, sendo raros também os espaços de escuta dessas pessoas, o que contribui para agravar ainda mais esse quadro e para a sua disseminação. Para os autores, é necessário conhecer a automutilação a partir da experiência da própria pessoa que a vivencia, sendo necessário que sejam desenvolvidas ações que possibilitam a escuta individual e coletiva desse público, como por exemplo, por meio de rodas de conversa sobre o tema.

Isso se justifica porque a falta de compreensão do que é a automutilação contribui para que a escola se torne um ambiente pouco acolhedor e adoecedor. Trata-se de um fenômeno multifatorial que possui alta abrangência e disseminação entre os jovens e adolescentes, especialmente em decorrência do fluxo rápido de informações, especialmente por meio das redes sociais. Além disso, o despreparo de gestores e professores desemboca em atitudes rotulatórias, estigmatizatórias e excludentes, que comumente contribui para que essas pessoas sejam culpabilizadas pelo seu próprio 
sofrimento psíquico, julgamento que piora ainda mais o quadro, pois a vegonha faz com que não consigam buscar ajuda, o que pode evoluir para uma tentativa de suicídio (EPIPHANIO; GUIMARÃES, 2019).

Finalmente, concordamos com Epiphanio e Guimarães (2019) sobre quão desafiador é escutar o ambiente escolar, tendo em vista que o aumento da incidência da automutilação é reflexo do mal-estar de nossa sociedade, e que ao escutarmos a escola “[...] nos deparamos com o ambiente que tem a intenção de formar pessoas e cidadãos que irão compor o mundo em que vivemos. A escola espelha o mundo à sua volta e a forma que as relações se manifestam" (p. 16).

\section{CONSIDERAÇÕES FINAIS}

Reafirmamos aqui a complexidade inerente ao fenômeno da automutilação, apresentando significados expressivos para os seus praticantes, que em sua maioria são representados por sujeitos femininos na faixa etária da adolescência. Consideramos que este fenômeno tem requerido cada vez mais atenção de diferentes estudiosos, das mais variadas áreas do conhecimento humano, em decorrência do aumento de sua incidência em diferentes instituições humanas, especialmente nas escolas, chegando a configurar um problema de saúde pública.

Ancorados no referencial teórico psicanalítico, argumentamos a necessidade de que a automutilação seja, a priori, compreendida como um modo de subjetivação, uma forma que o sujeito encontra para dizer aquilo que está encoberto, quando na dificuldade de utilizar o recurso da palavra. Destacamos ainda que, estando o sujeito feminino mais afeito à angústia, por estar na posição de mulher e, consequentemente, não-toda, corrobora para que experimente esse gozo Outro como não sendo o do Um fálico e que haja uma vivência de desvario e desarrazoamento, fazendo com que acabe ficando fora do laço social.

Diante disso, a perspectiva lacaniana de acting out, pode nos ajudar a ter uma outra leitura do fenômeno da automutilação, sendo compreendida como uma mensagem que o sujeito endereça ao Outro, como um pedido de socorro. Nesse sentido, assumimos o argumento de Dettmer (2018) de que as escolas necessitam promover ações de prevenção e intervenção que possam ir além do olhar predominantemente biomédico e patologizante sobre esse fenômeno, que contribui para atitudes de exclusão e discriminação no ambiente 
escolar e na sociedade como um todo, para que seja possível o acolhimento desses pedidos inconscientes de socorro e sejam propostas políticas públicas que levem em consideração as opiniões destas pessoas.

\section{REFERÊNCIAS}

ALMEIDA, R. S. et al. A prática da automutilação na adolescência: o olhar da psicologia escolar $\backslash$ educacional. Cadernos de Graduação: Ciências Humanas e Sociais. Maceió \AL, v. 4, n. 3, Maio, 2018, p. 147-160. Disponível em: <https://periodicos.set.edu.br/index.php/fitshumanas/article>. Acesso em 22 Abr. 2021.

ALMEIDA, R. S. Historiografia das práticas de automutilação: produção de sentidos em narrativas de jovens no ensino superior. 2021, 88 f. Dissertação (Mestrado em Psicologia) - Instituto de Psicologia. Universidade Federal de Alagoas, Maceió, 2021. Disponível em: <https://ip.ufal.br/pt-br/pos-graduacao/mestrado-empsicologia/documentos/dissertacoes/2021/rodrigo_dissertao_com_ficha_catalogrfica.pdf /view>. Acesso em 22 Nov. 2021.

ALMEIDA R. S. et al. Reflexões sobre a pandemia da COVD-19 e seus impactos para as práticas de automutilação. Brazilian Journal of Development. Curitiba, v.7, n.3, Mar. 2021, p. 22456-22472, Disponível em:

<https://www.brazilianjournals.com/index.php/BRJD/article/view/25820/20499>. Acesso em 07 Jul. 2021. DOI:10.34117/bjdv7n3-116.

ALMEIDA R. S. et al. A Acessibilidade atitudinal de pessoas que praticam automutilação na escola. Brazilian Journal of Development. Curitiba, v.7, n.6, Jun. 2021, p. 56572-56589. Disponível em: $\langle$ https://www.brazilianjournals.com/index.php/BRJD/article/view/31035/pdf $>$. Acesso em 07 Jul. 2021. DOI:10.34117/bjdv7n6-187.

ARATANGY, E. W. et al. (Org.). Como lidar com a automutilação: guia prático para familiares, professores e jovens que lidam com o problema da automutilação. São Paulo: Hogrefe, 2017.

BERNAL, E. P. Considerações psicanalíticas a respeito da automutilação. 2019, 125f. Dissertação (Mestrado em Ciências) - Instituto de Psicologia. Universidade de São Paulo, São Paulo, 2019. Disponível em:

<www.teses.usp.br/teses/disponiveis/47/471117062019100>. Acesso em 31 Mar. 2021.

DEMANTOVA, A. G. Automutilação na adolescência: corpo marcado, corpo atacado. Curitiba: CRV, 2020.

DETTMER, S. E. S.; COSTA, J. B. O. Gestão e a construção do cutting: um resgate histórico de como a reestruturação produtiva afeta a saúde no contexto escolar. In: IV SEMINÁRIO INTERNACIONAL DE REPRESENTAÇÕES SOCIAIS, 
SUBJETIVIDADE E EDUCAÇÃO - SIRSSE, Anais do EDUCERE - XIII

Congresso Nacional de Educação, Grande Dourados: Mesa Redonda: Formação de Professores: contextos, sentidos e práticas, 2017, p. 4731-4744. Disponível em: <educere.puc.br/anais.html>. Acesso em 14 Jan. 2021.

DETTMER, S. E. S. Cutting: uma caracterização do fenômeno em escolas de Dourados (MS). 2018, 132 f. Dissertação (Mestrado em Psicologia) - Programa de Pós-Graduação em Psicologia. Fundação Universidade Federal da Grande Dourados, Dourados $\backslash$ MS, 2018. Disponível em: <http://repositorio.ufgd.edu.br/jspui/handle/prefix/1130>. Acesso em 28 Mar. 2021.

DIAS, I. M. S. Cutting - a automutilação em perspectiva lacaniana. 2019, $74 \mathrm{f}$.

Dissertação (Mestrado em Psicanálise) - Programa de Pós-Graduação em Psicanálise, Saúde e Sociedade. Universidade Veiga de Almeida, Rio de Janeiro, 2019. Disponível em:

<https://www.uva.br/sites/default/files/cutting_a_automutilacao_em_perspectiva_lacani ana_ines_mendonca_dos_santos_dias.pdf>. Acesso em 08 Jul. 2021.

EPIPHANIO, E. H.; GUIMARÃES, S. G. L. E Como está a saúde mental na educação? Reflexões sobre comportamentos autodestrutivos no ambiente escolar. In: ARAÚJO, L. P. et al. Comportamento e suicídio: o suicídio e seus atores sociais. Petrolina: UNIVASF, 2019, p. 13-20.

EULÁlio, A. Amores loucos: a devastação materna e nas parcerias amorosas. Belo Horizonte: Artesã, 2020.

FALCÃO, J. Cortes \& cartas: estudos sobre automutilação. Curitiba: Appris, 2021.

FORTES, I. A automutilação e a dimensão da alteridade. In: NOVAES, J.; VILHENA, J. (Orgs.) Que corpo é este que anda comigo? Corpo, imagem e sofrimento psíquico. Curitiba: Appris, 2016, p. 103-109.

LACAN, J. O Seminário, livro 10: A angústia. 1962-1963. Rio de Janeiro: Zahar, 2005.

LACAN, J. O Seminário, livro 11: Os quatro conceitos fundamentais da psicanálise. 1964. $2^{\text {a }}$ ed. Rio de Janeiro: Zahar, 2008.

LACAN, J. O Seminário, livro 17: O avesso da psicanálise. 1969-1970. Rio de Janeiro: Zahar, 2008.

LACAN, J. O Seminário, livro 20: Mais, ainda (1972-1973). Rio de Janeiro: Zahar, 2008.

LACAN, J. O aturdito. In: LACAN, J. Outros escritos. 1972. Rio de Janeiro: Zahar, 2003, p. 448-497.

LACAN, J. O Seminário, livro 23: O Sinthoma (1975-1976). Rio de Janeiro: Zahar, 2007. 
MARCOS, C. A Escrita do caso clínico em psicanálise: uma lógica não-toda. In:

FERREIRA, T.; VORCARO, A. (Orgs.). Pesquisa e psicanálise: do campo à escrita. Belo Horizonte: Autêntica, 2018, p. 97-110.

MIRANDA, E. R. Desarrazoadas: devastação e êxtase. Rio de Janeiro: Contra Capa, 2017.

QUINET, A. A descoberta do inconsciente - do desejo ao sintoma. $3^{\mathrm{a}}$ ed. Rio de Janeiro: Zahar, 2008.

REIS, M. N. Automutilação: o encontro entre o real do sofrimento e o sofrimento real. Revista Polêmica. Rio de Janeiro, v. 18, n. 1, Mar. 2018, p. 50-67. Disponível em: $<$ https://www.e-publicacoes.uerj.br/index.php/polemica/article/view/36069>. Acesso em 18 Jul. 2021. DOI: 10.12957/polemica.2018.36069.

SOLER, C. O que Lacan dizia das mulheres. Rio de Janeiro: Zahar, 2005.

SOLER, C. Declinações da angústia: Curso 2000 - 2001. São Paulo: Escuta, 2012.

SOLER, C. Adventos do real: da angústia ao sintoma. $2^{a}$ ed. São Paulo: Aller, 2021. 